\title{
PECULIARITIES OF DEGRADATION OF METAL IN WELDED JOINTS OF STEAM PIPELINES
}

\author{
V.V. DMITRIK ${ }^{1}$, O.V. SOBOL ${ }^{1}$, M.A. POGREBNOJ ${ }^{1}$ and T.A. SYRENKO ${ }^{2}$ \\ ${ }^{1}$ National Technical University «Kharkov Polytechnic Institute» \\ 21 Frunze Str., 61002, Kharkov, Ukraine. E-mail: svarka126@ukr.net \\ ${ }^{2}$ Kharkov Machine-Building College \\ 79 Plekhanovskaya Str., 61068, Kharkov, Ukraine
}

\begin{abstract}
Extension of life of steam pipelines, operated under creep conditions, determines the necessity of evaluation of their damageability and in many respects depends on carbide transformations in metal. The work considers peculiarities of diffusion and structure of carbide phases in metal of welded joints of pearlite steels after long-term operation. It is determined that concentration of coagulating carbide phases $\left(\mathrm{M}_{23} \mathrm{C}_{6}, \mathrm{M}_{7} \mathrm{C}_{3}\right.$ etc. $)$ at the boundaries of $\alpha$-phase grains promotes for nucleation of creep pores and fatigue cracks, that causes brittle fracture of metal of welded joints. 18 Ref., 8 Figures.
\end{abstract}

Key words: steam pipeline welded joints, carbide phases, creep pores, fatigue cracks, damageability, operation life

Running of steam pipelines of Ukrainian HPP makes around 200-300 thousand hours, that for

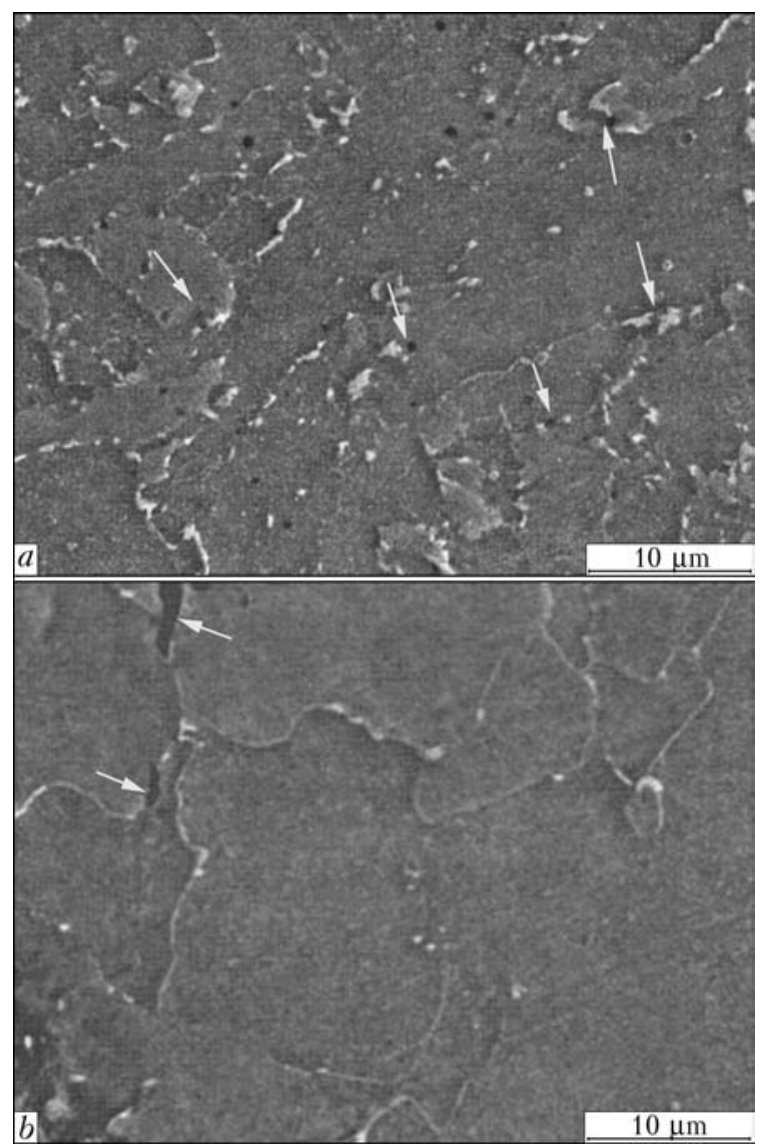

Figure 1. Microstructure of area of HAZ metal overheating of welded joint from steel $12 \mathrm{Kh} 1 \mathrm{MF}: a-$ creep micropores in area of incomplete recrystallization; $b-$ fatigue microcracks; defects are indicated by arrows

(c) V.V. DMITRIK, O.V. SOBOL, M.A. POGREBNOJ and T.A. SYRENKO, 2015 most of them exceeds their design life (including extended) as well as significantly outdo fleet life.

Metal of welded joints of steam pipelines is characterized by structural, chemical and mechanical inhomogeneity, formation of which is promoted by welding heating at their manufacture. Namely, inhomogeneity under conditions of long-term operation provides for more intensive physical-chemical processes in welded joint metal than in the base metal, that, respectively, provokes its degradation and limits the life.

Evaluation of damageability level in welded joints of steam pipelines of long-term operation, which allows specifying their residual life, is of current importance. Investigation of peculiarities of physical-chemical processes, taking place in welded joint metal, is relevant for evaluation.

It is a well-known fact that welded joints of elements of steam conduit channel from $15 \mathrm{Kh} 1 \mathrm{M} 1 \mathrm{~F}$ and $12 \mathrm{Kh} 1 \mathrm{MF}$ steels, being operated under $545-585{ }^{\circ} \mathrm{C}$ temperature and $20-25 \mathrm{MPa}$ pressure [1-7], mostly suffer from damages at long-term running. Transfer of power generating units in cycling operation mode provides for acceleration of their damageability. Damageability of metal of welded joints mainly takes place by creep and fatigue mechanisms, which are forced by corrosion constituent (Figure 1). Damageability by creep mechanism is characterized by formation of nucleation (critical) pores of around $0.03-0.07 \mu \mathrm{m}$ size as well as their coarsening up to $3-7 \mu \mathrm{m}$, further branching and transformation of pores in creep cracks.

The most intensive formation of creep pores is observed in areas of incomplete recrystallization and fusion of HAZ of welded joints in their external, most elongated area. The fatigue cracks 


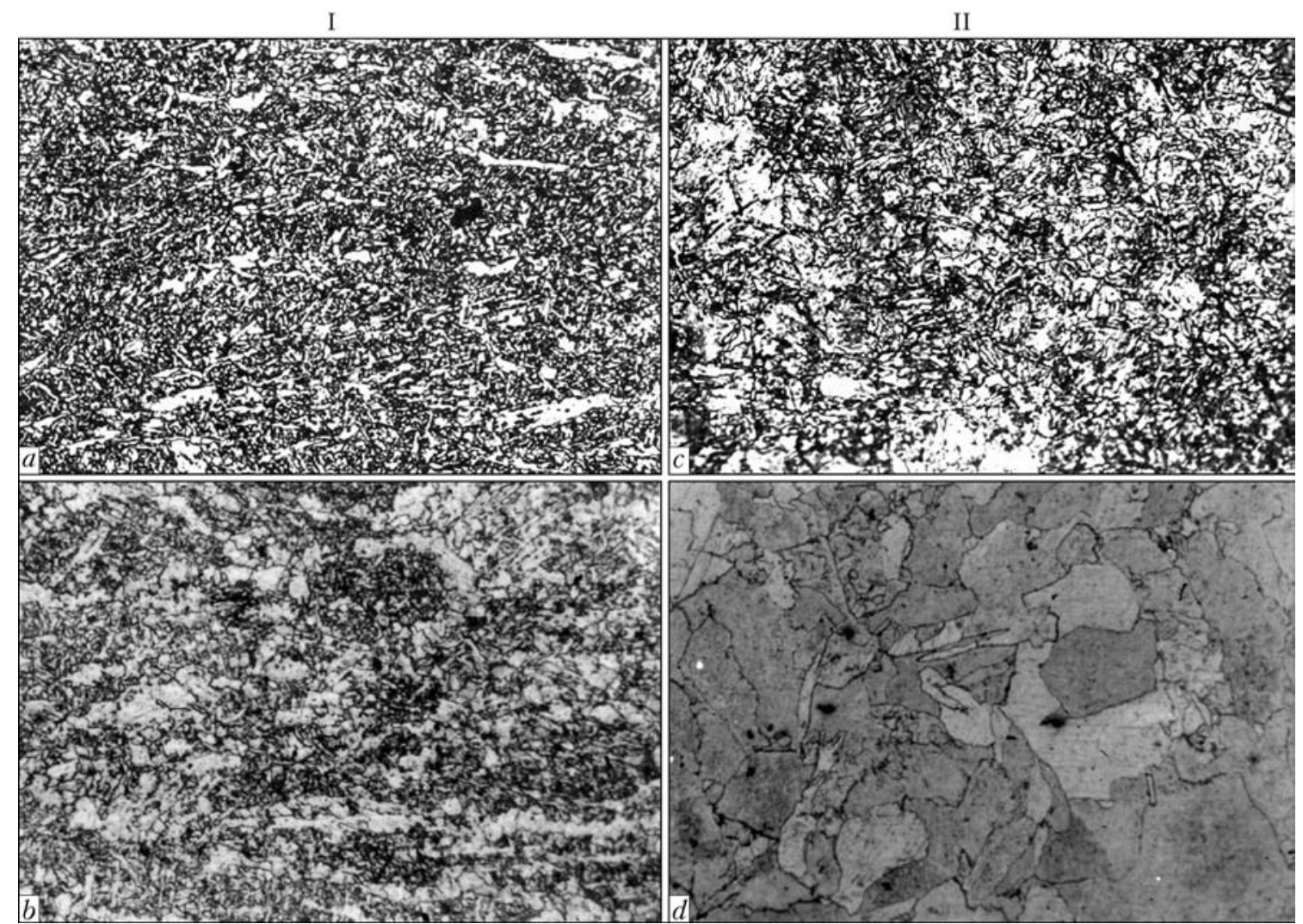

Figure 2. Microstructure $(\times 100)$ of welded joint from steel 15Kh1M1F: $a, c-$ initial structure; $b-$ after $200,000 \mathrm{~h}$ running; $d-280,000$ h; I - weld metal (alloy 09KhMF); II - area of HAZ metal overheating

have the most intensive development in areas of fusion, overheating and incomplete recrystallization of HAZ metal, rarely in weld and base metal. The fatigue cracks are mainly formed on internal surface of welded joints. Damageability of metal of welded joints is to be considered as an effect of its degradation, which is provided by physical-chemical processes and detected by means of examination of its structure as the most reliable parameter.

Structure of welded joints (areas of HAZ, weld and base metals) in process of long-term operation is transformed with different rate in ferrite-carbide mixtures different between themselves (Figure 2). Determination of $\alpha$-phase grain average size; average size of carbides and density of their distribution along the grain body; form, size and distribution of carbides along the grain boundaries; amount of pores and their form, location, average and maximum size as well as specific porosity of metal of welded joints are relevant for evaluation of structure degradation.

Structural changes in welded joints are caused by physical-chemical processes, investigation of which is relevant for reduction of such changes.

Diffusion displacement of atoms of chromium and molybdenum from central zones of $\alpha$-phase crystals in their near-boundary zones [8] takes place under conditions of operating stresses and temperature. Diffusion in inter-grain boundaries, i.e. boundary diffusion, takes place simultaneously at larger rate. Coefficients of boundary and volumetric diffusion are not constant values. Therefore, deviation from Arrhenius law is noted in steam pipeline metal.

Fischer model [9] with introduction of some specifications [10] is more appropriate than other ones for investigation of flows of boundary and volumetric diffusion as separated. Such specifications allow determining dependencies of coagulation of carbides of the 1st group by length. Considering value of diffusion coefficients [8], Fick's equation applicable to boundary diffusion of atoms of chromium and molybdenum is written as:

$$
\left\{\begin{array}{l}
\frac{d(\mathrm{Cr})}{d t}=-\frac{d j_{y}}{d y}-2 \frac{1}{\delta} j_{x}=D_{r} \frac{d^{2}(\mathrm{Cr})}{d y^{2}}+\frac{2 D_{\mathrm{v}}}{\delta} \frac{d(\mathrm{Cr})}{d x} \\
\frac{d(\mathrm{Mo})}{d t}=-\frac{d j_{y}}{d y}-2 \frac{1}{\delta} j_{x}=D_{r} \frac{d^{2}(\mathrm{Mo})}{d y^{2}}+\frac{2 D_{\mathrm{v}}}{\delta} \frac{d(\mathrm{Mo})}{d x}
\end{array}\right.
$$

Here, $\delta$ is the width of grain boundary;

$$
j_{x}=-D_{\mathrm{v}} \frac{d C}{d x},
$$

and similar

$$
j_{y}=-D_{\mathrm{b}} \frac{d C}{d r},
$$


SCIENTIFIC AND TECHNICAL

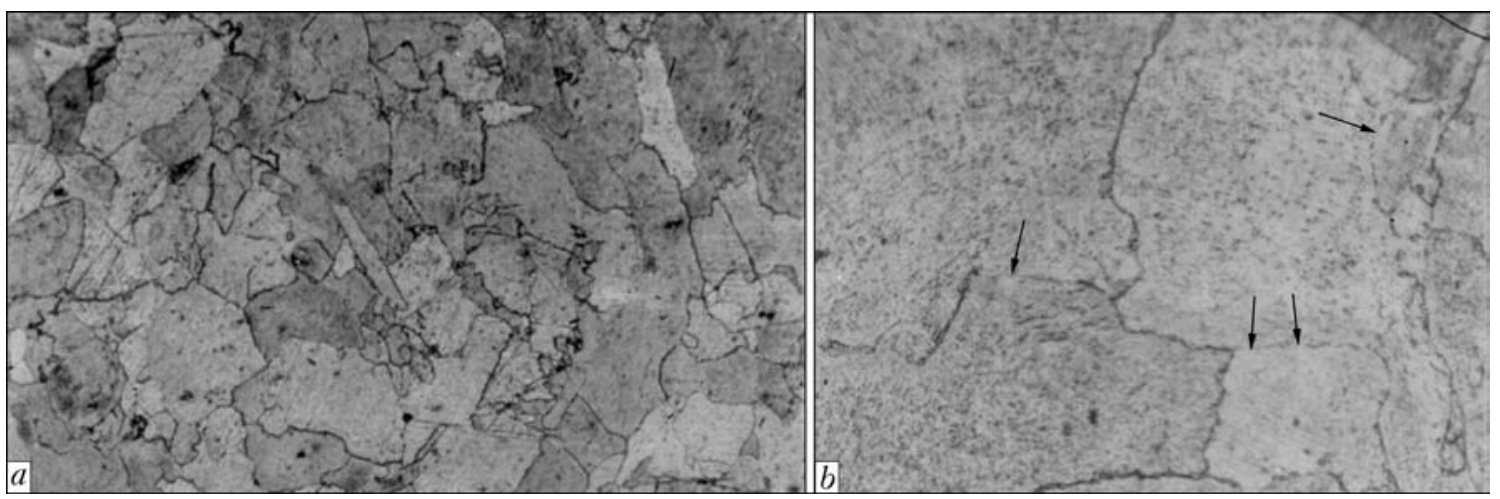

Figure 3. Microstructure of welded joint of main steam line from $15 \mathrm{Kh} 1 \mathrm{M} 1 \mathrm{~F}$ steel (HPP, Energodar city) with life of 180,000 h: $a$ - weld metal (alloy 09KhMF) $(\times 100) ; b$ - area of HAZ metal overheating $(\times 750)$; change of grain boundary structure is indicated by arrows

where $C=\mathrm{Cr}, \mathrm{Mo} ; D_{\mathrm{b}}$ is the coefficient of boundary diffusion; $D_{\mathrm{v}}-$ volumetric one.

Penetration of diffusing atoms of chromium and molybdenum in boundary zone of $\alpha$-phase crystal was determined taking into account $D_{\mathrm{b}}$ and $D_{\mathrm{v}}$ as well as mean displacement square [8].

Resolution of known methods, allowing determining form and size of isolated boundary and volumetric diffusion flows, is not sufficient. Specific near-boundary volume of $\alpha$-phase is resolution captured in use of surface microprobe analysis [11, 12], that, however, allows receiving acceptable results taking into account error. It was determined that $D_{\mathrm{b}} / D_{\mathrm{v}}$ relationship for metal of welded joints lies in $10^{2}-10^{3}$ range and depends on conditions of their operation, chemical composition, structure and other factors. It is determined that energy of activation of boundary diffusion $E_{\mathrm{b}}$ is lower than volumetric one $E_{\mathrm{v}} . E_{\mathrm{b}}$ and $E_{\mathrm{v}}$ are variable values and their relationship makes from 0.40 to 0.72 . Change of intensity of diffusion flows of chromium and molybdenum and, respectively, their energies of activation, is

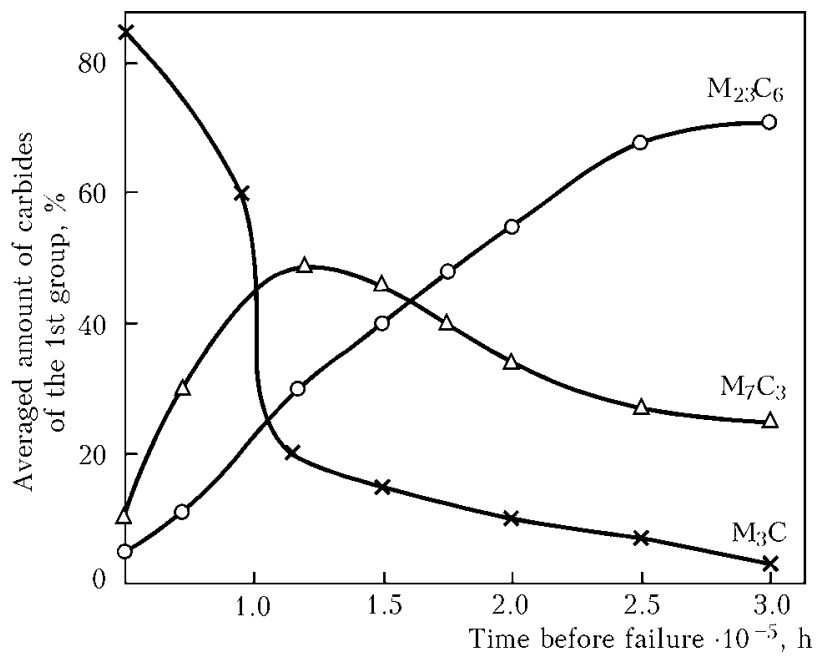

Figure 4. Experimental data on change of amount of carbides of the 1st group in metal of area of HAZ incomplete recrystallization in welded joint of live stem line from steel $12 \mathrm{Kh} 1 \mathrm{MF}$ caused by respective changes of chemical potentials.

It is determined that value of coefficient of chromium boundary diffusion in weld metal structure (alloy 09KhMF) (Figure 3,a) makes $(1.1-2.2) \cdot 10^{-14} \mathrm{~cm}^{2} / \mathrm{s}$, and for structure $\left(\mathrm{Fi}^{-}\right.$ gure $3, b)$ it is $(2.7-3.1) \cdot 10^{-14} \mathrm{~cm}^{2} / \mathrm{s}$. Value of coefficient depends on structure, size and form of grain boundary. $D_{\mathrm{b}}$ value is lower for low-angle boundaries having misorientation not more than $12^{\circ}$ (fine grain structure) in comparison with similar parameters for coarse grain with misorientation more than $15^{\circ} . D_{\mathrm{b}}$ value depends on parameters of operation mode, i.e. temperature, stress, overheating, start-stops as well as duration of welded joint running, their structure and chemical composition. Values of given coefficient are changed under creep conditions, when recrystallization processes at long-term running provide for local change of grain boundaries ( $\mathrm{Fi}-$ gure $3, b$ ).

Concentration profile $\operatorname{Cr}(x, y, t)$ and $\operatorname{Mo}(x$, $y, t)$ are determined with the help of X-ray spectrography as well as surface microprobe analysis. It was determined that level of chrome segregation at running of welded joints of more than $270,000 \mathrm{~h}$ can, for example, make up to $3-5 \%$ $[11,12]$ at boundaries of crystals of $\alpha$-phase and in their near-boundary zones.

Effect of vanadium to carbon relationship [1] has to be taken into account in consideration of structure stability. Carbides $\mathrm{M}_{3} \mathrm{C}, \mathrm{M}_{7} \mathrm{C}_{3}, \mathrm{M}_{23} \mathrm{C}_{6}$ of the 1st group and $\mathrm{Mo}_{2} \mathrm{C}$ and $\mathrm{VC}$ of the $2 \mathrm{nd}$ group are present in metal at $\mathrm{V} / \mathrm{C} \geq 2$.

Peculiarities of carbide phase structure as well as kinetics of their formation and growth are relevant to study for specification of degradation of welded joint metal. Intensity of phase formation as well as their coagulation in structure of weld metal, HAZ areas and base metal had some differences. Identifying of carbides taking into account procedure of study [13] was carried out 
based on results of decoding of microdiffraction images of particles being extracted in replicate from section as well as using method of electronprobe microanalysis on scanning electron microscope JSM-820. The average size between carbides of the 1st and 2nd groups along the $\alpha$-phase grain body was obviously different. Level of difference for areas of HAZ as well as deposited and base metal was also different.

Quantitative change of carbide phases takes place in metal of welded joints during long-term operation. Decrease of $\mathrm{M}_{3} \mathrm{C}$ and increase of $\mathrm{M}_{7} \mathrm{C}_{3}$ carbides [14] are noted at running to $150,000 \mathrm{~h}$. It was determined that further running provides for reduction of $\mathrm{M}_{7} \mathrm{C}_{3}$ and increase of $\mathrm{M}_{23} \mathrm{C}_{6}$ amount (Figure 4).

$\mathrm{X}$-ray structural examination of carbide phases, extracted from welded joint of steam pipeline from $12 \mathrm{Kh} 1 \mathrm{MF}$ steel (running $200,000 \mathrm{~h}$ ), were carried out on X-ray diffraction meter Siemens D-500, which uses powder method for measurements, in monochromatized copper irradiation with graphite monochromator in reflected beam. Difractograms were taken at $10^{\circ} \leq$ $\leq 2 \theta \leq 140^{\circ}$ angle interval with scanning step $0.02^{\circ}$ and pulse accumulation time $75 \mathrm{~s}$ in each point (Figure 5). Identification of phases was carried out in accordance with PDF-4 card index. Rietveld method [15] was used for calculations. Data of works $[16,17]$ were applied as test models of structures of carbide phases.

Letus consider carbide phase structure. Cementite $\mathrm{M}_{3} \mathrm{C}(\mathrm{Fe}, \mathrm{Cr})_{3} \mathrm{C}$ has complex orthorombic lattice with the parameters, A: $a-4.514$; $b-5.079 ; c-6.730$. X-ray analysis determined that chromium can substitute up to $19 \%$ (at.) of iron in $\mathrm{M}_{3} \mathrm{C}$ (structure of welded joint from steel $15 \mathrm{Kh} 1 \mathrm{M} 1 \mathrm{~F})$. ( $\mathrm{Fe}, \mathrm{Cr})_{3} \mathrm{C}$ is formed at local concentration of chromium from 1.0 to $2.5 \%$. No atoms of molybdenum were found in $\mathrm{M}_{3} \mathrm{C}$. Increase of chromium concentration more than $2.5 \%$ promotes for formation of trigonal carbide $(\mathrm{Fe}, \mathrm{Cr})_{7} \mathrm{C}_{3}$, having hexagonal lattice of the following parameters, A: $a-4.523 ; c-13.98$. $\mathrm{M}_{7} \mathrm{C}_{3}$ precipitates were of spherical or polyhedrous form, melting temperature $1669{ }^{\circ} \mathrm{C}$ and density $6.92 \mathrm{~g} / \mathrm{cm}^{3} . \mathrm{M}_{7} \mathrm{C}_{3}$ carbide is formed in steels $15 \mathrm{Kh} 1 \mathrm{M} 1 \mathrm{~F}$ and $12 \mathrm{Kh} 1 \mathrm{MF}$ at tempering (730-750 $\left.{ }^{\circ} \mathrm{C}, 3-5 \mathrm{~h}\right)$ as well as resulting from $\left(\mathrm{M}_{3} \mathrm{C}+\mathrm{C}\right) \rightarrow \mathrm{M}_{7} \mathrm{C}_{3}$ reaction in process of their long-term operation.

Cubic carbide $\mathrm{M}_{23} \mathrm{C}_{6}$ (5-7 \%) appears together with $\mathrm{M}_{7} \mathrm{C}_{3}$ after tempering. $\mathrm{M}_{7} \mathrm{C}_{3}$ has high capability to dissolution of iron atoms that is provided by intensive exchange reactions between $\alpha$-phase crystals and $\mathrm{M}_{7} \mathrm{C}_{3}$, resulting to

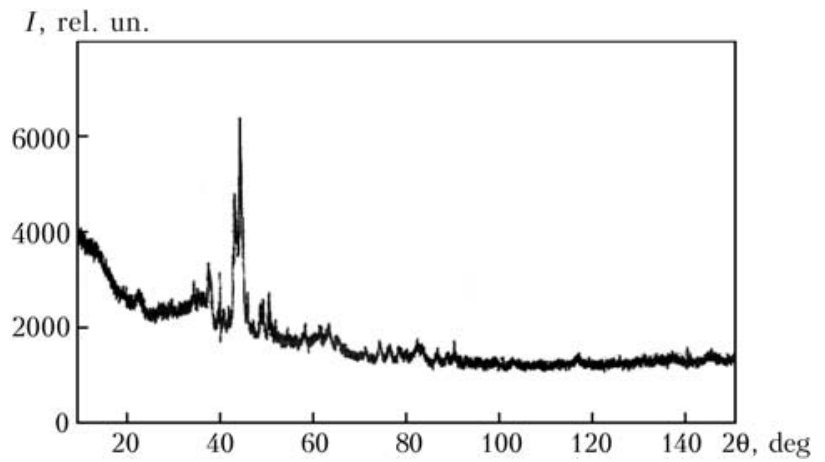

Figure 5. Experimental X-ray pattern of $\mathrm{M}_{23} \mathrm{C}_{6}$ carbide phase

$\mathrm{M}_{7} \mathrm{C}_{3}$ coagulation via lattice building-up. $\mathrm{M}_{23} \mathrm{C}_{6}$ carbides are formed at presence of local chromium concentration more than $3 \%$ (running of welded joints $130,000-150,000 \mathrm{~h}$ ) by means of $\mathrm{M}_{7} \mathrm{C}_{3} \rightarrow$ $\rightarrow \mathrm{M}_{23} \mathrm{C}_{6}$ reaction. They have complex structure representing itself face-centered cube of 10.64 A parameters (Figure 6).

$\mathrm{X}$-ray pattern (see Figure 5) shows that $\mathrm{M}_{23} \mathrm{C}_{6}$ carbide has significant level of crystalline lattice deformation. Significant widening of reflexes is observed. It is promoted by reduced size of crystallites and presence of microdeformations.

Investigation of phases using line-diagrams and PDF-4 card showed that cards of carbide $\mathrm{M}_{23} \mathrm{C}_{6}$ (28-646) and $\mathrm{M}_{3} \mathrm{C}$ ( $\alpha$-modification, cohenite, card 34-1) give the best correlation with experimentally observed image. It should be noted that some lines of experimental X-ray patterns did not correspond to card index data.

Determination of parameters [15] was carried out for phases studied by Rietveld method. It was verified that external distance between atoms in tetrahedral units is more than lattice parameter for $30-40 \%$. Tetrahedral ribs between cubes significantly exceed length of cube ribs. Local amorphism of $\mathrm{M}_{23} \mathrm{C}_{6}$ lattice is noted that

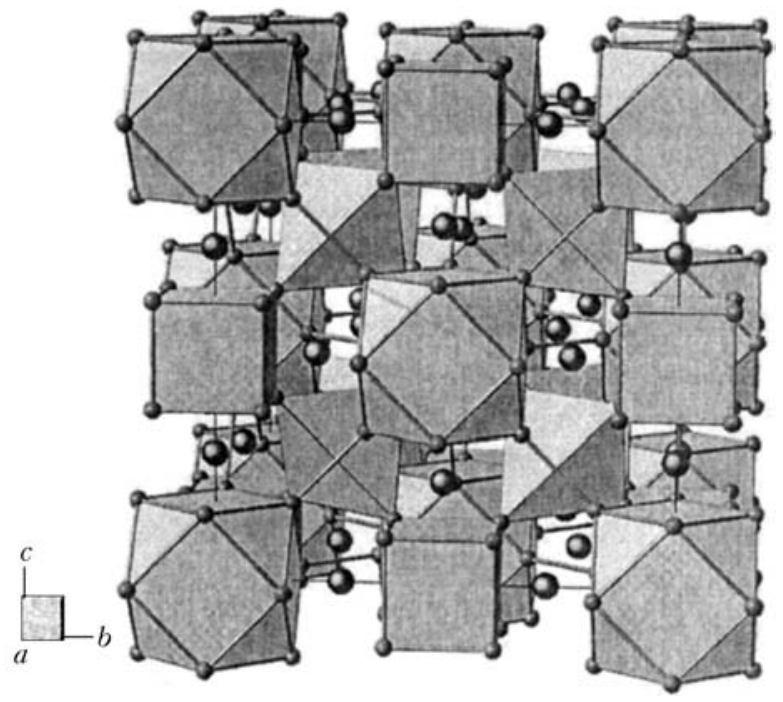

Figure 6. Model of face-centered lattice of $\mathrm{M}_{23} \mathrm{C}_{6}$ carbide 


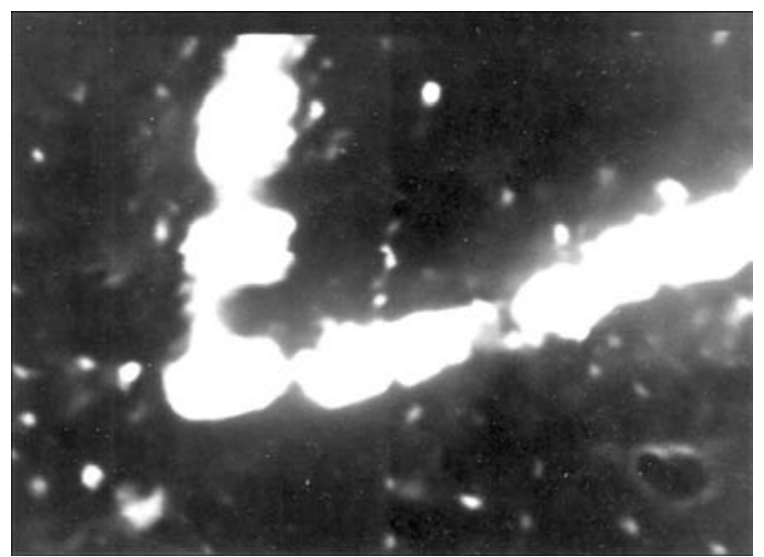

Figure 7. Demonstration of coalescence of $\mathrm{M}_{23} \mathrm{C}_{6}$ carbides at boundaries of $\alpha$-phase grains $(\times 7500)$

is, possibly, related with its building-up in process of coagulation by means of coalescence. The cube (Figure 6) includes 92 atoms of chromium and molybdenum as well as 24 atoms of carbon. It was determined that after $150,000 \mathrm{~h}$ of running atoms of molybdenum, having more affinity to carbon than atoms of chromium, displace them from $\mathrm{M}_{23} \mathrm{C}_{6}$ lattice points and atoms of chromium again react to form of $\alpha$-phase crystal. $\mathrm{M}_{23} \mathrm{C}_{6}$ density makes $6.97 \mathrm{~g} / \mathrm{cm}^{2}$.

Tendency to increase of amount of $\mathrm{VC}$ carbides is noted in metal of welded joints of long operation. Such an increase is promoted by release of carbon due to $\mathrm{M}_{7} \mathrm{C}_{3} \rightarrow \mathrm{M}_{23} \mathrm{C}_{6}$ reaction. Superfine vanadium carbide has cubic lattice of 4.154.16 A parameters, its density is $5.36 \mathrm{~g} / \mathrm{cm}^{3}$. VC is primarily formed in weld metal after tempering $\left(730-750{ }^{\circ} \mathrm{C}\right)$. Vanadium carbide has fiber form, effectively brakes dislocation movement that reduces creep effect. It was determined that VC carbides remain stable and do not coagulate in welded joint running up to $300,000 \mathrm{~h}$. Such a stability is promoted by low rate of exchange reactions between $\mathrm{VC}$ carbides and $\alpha$-phase crystals, since atoms of iron do not dissolve in VC.

It can be shown that welded joints from $12 \mathrm{Kh} 1 \mathrm{MF}$ steel have better heat resistance properties in process of long-term operation $\left(t_{\text {run }}>\right.$ $>270,000 \mathrm{~h}, T_{\text {op }} \leq 454^{\circ} \mathrm{C}$ ) under creep conditions than welded joints from steel $15 \mathrm{Kh} 1 \mathrm{M} 1 \mathrm{~F}$. Welded joints from steel $12 \mathrm{Kh} 1 \mathrm{MF}$ are less damaged by creep pores than joints from steel 15Kh1M1F.

Small amount of $\mathrm{Mo}_{2} \mathrm{C}$ was found in metal of welded joints from studied steels. It is a wellknown fact that $\mathrm{Mo}_{2} \mathrm{C}$ has hexagonal closepacked lattice with parameters, A: $a-3.022$; $c-4.724$. Melting temperature of $\mathrm{Mo}_{2} \mathrm{C}$ is $2000{ }^{\circ} \mathrm{C}$ and its density $9.18 \mathrm{~g} / \mathrm{cm}^{3}$. Molybdenum carbide has high stability in welded joint running to $300,000 \mathrm{~h}$, that is explained

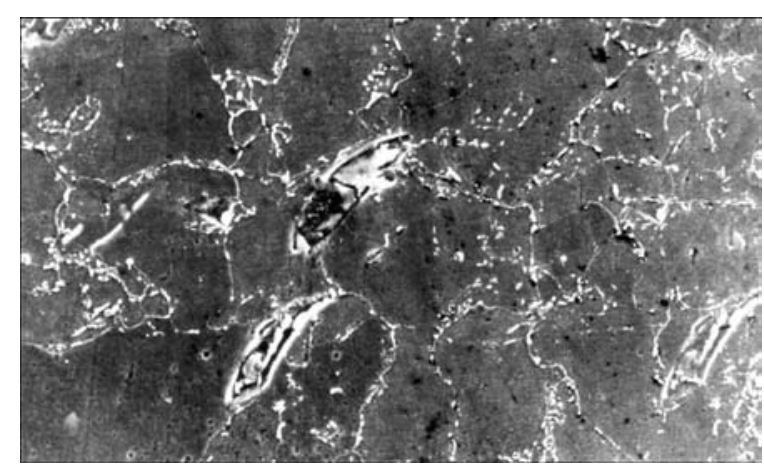

Figure 8. Microstructure $(\times 2000)$ of welded joint metal with creep pores and cracks

by its capability to dissolve iron and other elements of studied steels in small amount not more than $7 \%$.

Carbides' coagulation promotes for increase of spread of their concentrated location taking place due to building-up of their crystalline lattice, that is provoked by boundary diffusion (to larger extent) and volumetric (to lower extent) (Figure 7). $\mathrm{M}_{23} \mathrm{C}_{6}$ carbides form intermittent chains along the boundaries of $\alpha$-phase grains $[12,18]$. Creep pores are nucleated close to such carbides, transforming in crack in process of their development (Figure 8) [4, 11, 18].

Presence of carbide chains along the $\alpha$-phase grain boundaries promotes for reduction of interatomic cohesive forces, that provides also nucleation of fatigue cracks developing by creep mechanism.

It was determined that concentration of carbides has some variations in areas of HAZ metal as well as weld and base metals. Difference of carbide distribution along the $\alpha$-phase grain body and their boundaries is also noted. For example, structure of area of HAZ metal incomplete recrystallization in boundary zones and at boundaries (welded joints from steel $15 \mathrm{Kh} 1 \mathrm{M} 1 \mathrm{~F}$, running 276,000 h) included mostly $\mathrm{M}_{23} \mathrm{C}_{6}$ carbides (approximately $70 \%$ ), $\mathrm{M}_{7} \mathrm{C}_{3}$ carbides (around $20 \%$ ) and the rest was $\mathrm{M}_{3} \mathrm{C}, \mathrm{Mo}_{2} \mathrm{C}$ and $\mathrm{VC}$. $\alpha$-phase grains of $\mathrm{M}_{23} \mathrm{C}_{6}$ carbides made around $50 \%$ in central zone.

It was determined that studied physicalchemical processes, providing degradation of metal of welded joints of steam pipelines after their running more than $200,000 \mathrm{~h}$, promote $10-$ $20 \%$ decrease of mechanical properties of joints $[1-7,12,18]$.

\section{Conclusions}

1. Peculiarities of diffusion and structure of carbide phases in metal of welded structures of longterm operation from heat-resistant pearlite steels 
were found, that allowed specifying mechanism of its degradation.

2. It was determined that concentration of coagulating carbide phases (mainly $\mathrm{M}_{23} \mathrm{C}_{6}$ and $\mathrm{M}_{7} \mathrm{C}_{3}$ ) at boundaries of $\alpha$-phase grains promotes for nucleation of creep pores and fatigue cracks, providing damageability of metal of welded joints by creep mechanism.

1. Gladshtejn, V.I. (2007) Influence of running up to 350,000 hours on service characteristics and structure of cast body parts of turbines and fittings. Metallovedenie $i$ Term. Obrab. Metallov, 4, 24-32.

2. Khromchenko, F.A., Kalugin, R.N. (2004) Calculation-experimental method for evaluation of residual life of welded joints in steam pipelines. The Paton Welding J., 5, 6-11.

3. Rezinskaya, V.F., Grin, E.A. (2013) Current problems of safety assurance of heat-mechanic equipment in prolongation of its service life. Teploenergetika, $\mathbf{1}$, 17-24.

4. Dmitrik, V.V., Bartash, S.N. (2014) Peculiarities of degradation of metal of welded joints in steam pipelines of heat power plants. The Paton Welding J., 6/7, 29-30.

5. Sirotyuk, A.M., Kapty, O.V., Dmitrakh, I.M. et al. (2013) Expert system for evaluation of structural element fracture of pipelines of heat-and-power engineering system. Metody ta Prylady Kontr. Yakosti, 2, 126-136.

6. Trubachyov, V.M., Kamenskaya, N.I. (2012) Methods for evaluation of microdamageability of metal of steam pipelines in long-term operation of thermal power plant. Metallovedenie i Term. Obrab. Metallov, 8, 49-54.

7. Danyushevsky, I.A., Kupry, E.B., Malkin, M.R. et al. (2008) Evaluation of residual life taking into account microdamageability. Teploenergetika, 2, 12-17.
8. Dmitrik, V.V., Syrenko, T.A. (2012) To the mechanism of diffusion of chromium and molybdenum in the metal of welded joints of steam pipelines. The Paton Welding J., 10, 20-24.

9. Bokshtejn, B.S. (1978) Diffusion in metals. Moscow: Metallurgiya.

10. Gottshtajn, G. (2011) Physico-chemical principles of materials science. Moscow: BINOM.

11. Dmitrik, V.V., Baumer, V.N. (2007) Carbide phases and damageability of welded joints in long-term service. Metallofizika, Nov. Tekhnologii, 7, 937-947.

12. Dmitrik, V.V., Syrenko, T.A. (2010) Specifics of temper brittleness of steam pipeline welded joints. Energosberezhenie. Energetika. Energoaudit, 4, 2935.

13. Lashko, N.F., Zaslavskaya, L.V., Kozlova, M.N. et al. (1978) Physico-chemical and phase analysis of steels and alloys. Moscow: Metallurgiya.

14. Lanskaya, K.A. (1969) Heat-resistant steels. Moscow: Metallurgiya.

15. Rafaja, D., Lengauer, W., Ettmayer, P. et al. (1998) Rietveld analysis of the ordering in V8C7. J. Alloys and Compounds, 3, 60-62.

16. Fruchart, D., Chaudouet, P., Fruchart, R. (1984) Etudes structurales de composes de type cementite: effet de l'hydrogene sur $\mathrm{Fe}_{3} \mathrm{C}$ suivi par diffraction electronique spectrometrie moessbauer sur $\mathrm{FeCo}_{2} \mathrm{~B}$ et $\mathrm{Co} 3 \mathrm{~B}$ dopes au $57 \mathrm{Fe}$. J. Solid State Chemistry, 51, 246-252.

17. Rodriguez-Carvajal, J., Rossnel, T. (1988) Full Prof. 98 and Win PLOTR: New Windows 95/NT applications for diffraction. Commission for Powder Diffraction, International Union of Crystallography Newsletter 20, 5-8, 159

18. Dmitrik, V.V., Tsaryuk, A.K., Konyk, A.I. (2008) Carbide phases and damageability of welded joints of steam pipelines under creep conditions. The Paton Welding J., 3, 28-32.

Received 18.02.2015 